\title{
Identification of Laser Intensity Assuring the Destruction of Target Region of Biological Tissue Using the Gradient Method and Generalized Dual-Phase Lag Equation
}

\author{
Ewa Majchrzak $^{1} \cdot$ Lukasz Turchan $^{1} \cdot$ Marek Jasiński $^{1}$ (D) \\ Received: 9 November 2017 / Accepted: 9 July 2018 / Published online: 18 July 2018 \\ (c) The Author(s) 2018
}

\begin{abstract}
Temperature distribution in biological tissue is described by dual-phase lag model supplemented by appropriate boundary and initial conditions. Laser-tissue interactions are taken into account in the source function occurring in this model. The problem is solved using the finite difference method. Next, the Arrhenius integral which is a measure of tissue destruction is calculated. The inverse problem formulated here is to estimate the laser intensity assuring the destruction of this tissue region for which the Arrhenius integral exceeds the critical value.
\end{abstract}

Keywords Bioheat transfer - Generalized dual-phase lag model · Tissue destruction - Identification problem . Gradient method

\section{Introduction}

The goal of biological tissue artificial heating is to destroy the diseased fragments and to minimize the damage of surrounding healthy tissue. Artificial hyperthermia treatments are performed using, among others, the electromagnetic field or the laser action. In this paper, the influence of lasers heating on biological tissue is analyzed. In the planning of this type of treatment, the mathematical methods are used, which allow the laser intensity to be estimated, assuring the destruction of the target region of biological tissue. To analyze the problem discussed, the mathematical models describing the laser irradiation, the temperature distribution in the tissue domain and the tissue damage degree should be formulated (Jacques and Pogue 2008; Niemz 2007; Tuchin 2007; Welch 1984; Welch and van Gemert 2011). In the case of soft tissues, the scattering generally dominates over the absorption for wavelengths between 650 and $1300 \mathrm{~nm}$ and to determine the diffuse fluence rate the steady-state optical diffusion equation can

Marek Jasiński

marek.jasinski@polsl.pl

1 Silesian University of Technology, Konarskiego 18A, 44-100 Gliwice, Poland be taken into account (Dombrovsky 2012; Farrel et al. 1992; Fasano et al. 2010; Guo et al. 2003). The temperature field in the irradiated biological tissue can be described by the different mathematical models. Three of them result from the theory of continuum mechanics, namely Pennes (1948), Vernotte (1958) and dual-phase lag (Xu et al. 2008) models. These models are widely used in numerical modeling of thermal processes occurring in the laser-irradiated biological tissues, e.g. Afrin et al. 2012; Fanjul-Vélez et al. 2009; He et al. 2006; Hooshmand et al. 2015; Jaunich et al. 2008; Kim and Guo 2007; Narasimhan and Sadasivam 2013; Zhang et al. 2017; Zhou et al. 2009a, b. The second group of models is based on the theory of porous media (Vafai 2010) and then the biological tissue is divided into two regions: vascular region (blood vessel) and extravascular region (tissue). Using this approach, the generalized dual-phase lag model (GDPL) is formulated (Zhang 2009). This model is starting to be used to determine the tissue and blood temperatures in the heated tissues (Afrin et al. 2012; Jasiński et al. 2016; Kałuża et al. 2017; Majchrzak et al. 2015). Knowledge of temperature distribution allows one to estimate the degree of tissue destruction using so-called Arrhenius integral (Jasiński 2013; Niemz 2007) or thermal dose parameter (Sapareto and Dewey 1984).

So far, the laser-tissue interactions have been modeled as the direct problems. For the assumed intensity of the 
laser, the source function related to the laser heating, the temperature distribution and finally the degree of tissue destruction have been determined. In this paper, the inverse problem connected with the estimation of laser intensity assuring the destruction of target region of biological tissue is considered. At first, the direct problem using the finite difference method is solved. To describe the temperature distribution the generalized dual-phase lag model supplemented by appropriate boundary and initial conditions is applied. The source function in the GDPL equation resulting from the laser heating is associated with the total fluence rate, where its diffuse part is determined using the steady-state optical diffusion equation. The degree of tissue destruction is estimated on the basis of Arrhenius integral. Next, taking into account these values, the inverse problem is solved using the gradient method. In the final part, the results of computations are shown.

\section{Formulation of the Direct Problem}

An axially symmetrical domain of biological tissue exposed to the laser beam, as shown in Fig. 1, is considered. Thermal processes can be described by generalized dual-phase lag model (Majchrzak et al. 2015; Zhang 2009). This model consists of two coupled equations:

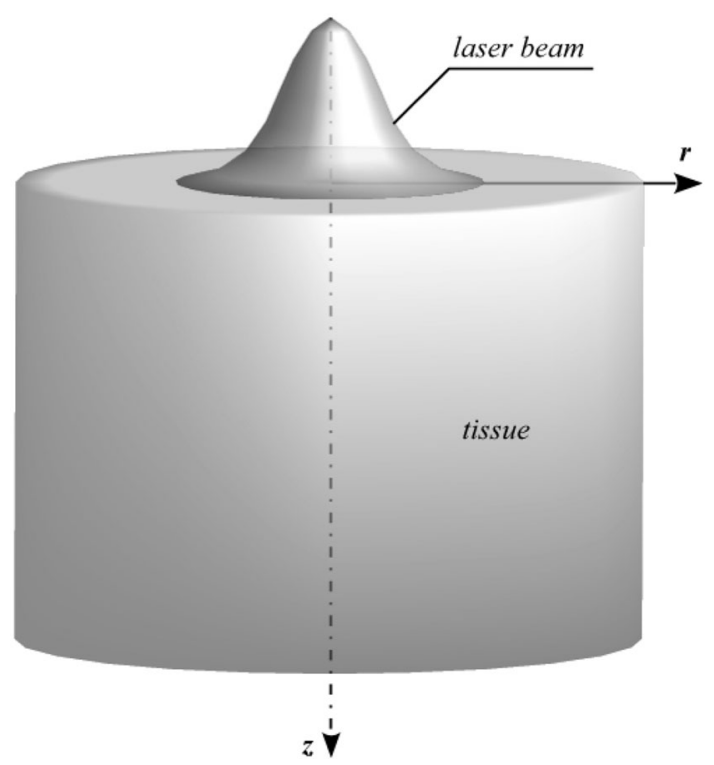

Fig. 1 The domain considered

$$
\begin{aligned}
C & {\left[\frac{\partial T(r, z, t)}{\partial t}+\tau_{q} \frac{\partial^{2} T(r, z, t)}{\partial t^{2}}\right] } \\
= & \Lambda \nabla^{2} T(r, z, t)+\Lambda \tau_{T} \frac{\partial}{\partial t}\left[\nabla^{2} T(r, z, t)\right] \\
& +G\left[T_{b}(r, z, t)-T(r, z, t)\right]+\varepsilon Q_{m b}+(1-\varepsilon) Q_{m}+Q_{e x}(r, z, t) \\
& +\frac{\tau_{q} C}{(1-\varepsilon) \rho c}\left[\varepsilon \frac{\partial Q_{m b}}{\partial t}+(1-\varepsilon) \frac{\partial Q_{m}}{\partial t}+\frac{\partial Q_{e x}(r, z, t)}{\partial t}\right],
\end{aligned}
$$

and

$T_{b}(r, z, t)=T(r, z, t)-\frac{\varepsilon \rho_{b} c_{b}}{G} \frac{\partial T_{b}(r, z, t)}{\partial t}$

where $\varepsilon$ is the porosity defined as the ratio of blood volume to the total volume, $C=\varepsilon \rho_{b} c_{b}+(1-\varepsilon) \rho c$ is the effective heat capacity $\left(\rho, \rho_{b}, c, c_{b}\right.$ are the densities and specific heats of tissue and blood, respectively), $\Lambda=\varepsilon \lambda_{b}+(1-\varepsilon) \lambda$ is the effective thermal conductivity $\left(\lambda, \lambda_{b}\right.$ are the thermal conductivities of tissue and blood, respectively), $G$ is the coupling factor, $\tau_{q}$ is the relaxation time, $\tau_{T}$ is the thermalization time, $Q_{m}$ and $Q_{m b}$ are the constant metabolic heat sources, $Q_{e x}(r, z, t)$ is the source function connected with the laser irradiation and $T(r, z, t)$ and $T_{b}(r, z, t)$ are the tissue and blood temperatures.

The generalized dual-phase lag Eq. (1) is supplemented by boundary condition (Mochnacki and Majchrzak 2017):

$$
\begin{aligned}
(r, z) & \in \Gamma_{0} \cup \Gamma: \\
-\Lambda & {\left[\mathbf{n} \cdot \nabla T(r, z, t)+\tau_{T} \frac{\partial[\mathbf{n} \cdot \nabla T(r, z, t)]}{\partial t}\right] } \\
& =q_{b}(r, z, t)+\tau_{q} \frac{\partial q_{b}(r, z, t)}{\partial t}
\end{aligned}
$$

where $\Gamma_{0}$ corresponds to the axis of symmetry, $\Gamma$ is the boundary of the cylinder, $\mathbf{n}$ is the normal outward vector, $\nabla T(r, z, t)$ is the temperature gradient and $q_{b}(r, z, t)$ is known boundary heat flux. Here, the no-flux boundary condition $q_{b}(r, z, t)=0$ is assumed. It should be noted that for strongly scattering tissues (like the soft tissues analyzed here), laser heating is considered as a body heat source but the irradiated surface is thermally insulated (Afrin et al. 2012). Thus, on the upper surface of the domain considered $q_{b}(r, z, t)=0$ is also assumed.

The initial conditions are also given:

$t=0: \quad T(r, z, t)=T_{p},\left.\quad \frac{\partial T(r, z, t)}{\partial t}\right|_{t=0}=w(r, z)$

where $T_{p}$ is known temperature and $w(r, z)$ is the initial heating rate.

The ordinary differential Eq. (2) is supplemented by condition

$t=0: \quad T_{b}(r, z, t)=T_{p}$.

Source function $Q_{e x}(r, z, t)$ connected with the laser heating can be defined as follows (Kim et al. 1996): 
$Q_{e x}(r, z, t)=\mu_{a} \phi(r, z) p(t)$

where $\mu_{a}[1 / \mathrm{m}]$ is the absorption coefficient, $\phi(r, z)$ [W/ $\left.\mathrm{m}^{2}\right]$ is the total light fluence rate and $p(t)$ is the function equal to 1 when the laser is on and equal to 0 when the laser is off.

The total light fluence rate $\phi(r, z)$ is the sum of collimated part $\phi_{c}$ and diffuse part $\phi_{d}$ (Gardner et al. 1996; Guo et al. 2003; Kim et al. 1996)

$\phi(r, z)=\phi_{c}(r, z)+\phi_{d}(r, z)$.

In the case of soft tissues, to determine the diffuse fluence rate the steady-state optical diffusion equation (Farrel et al. 1992; Fasano et al. 2010; Welch and van Gemert 2011) should be solved

$(r, z) \in \Omega: \quad D \nabla^{2} \phi_{d}(r, z)-\mu_{a} \phi_{d}(r, z)+\mu_{s}^{\prime} \phi_{c}(r, z)=0$

where

$D=\frac{1}{3\left[\mu_{a}+(1-g) \mu_{s}\right]}$

and $\mu_{s}^{\prime}=(1-g) \mu_{s}[1 / \mathrm{m}]$ is the effective scattering coefficient ( $\mu_{s}$ is the scattering coefficient, $g$ is the anisotropy factor).

Equation (8) is supplemented by boundary conditions

$$
\begin{array}{r}
(r, z) \in \Gamma: \quad-D \mathbf{n} \cdot \nabla \phi_{d}(r, z)=\frac{\phi_{d}(r, z)}{2} \\
(r, z) \in \Gamma_{0}: \quad-D \mathbf{n} \cdot \nabla \phi_{d}(r, z)=0 .
\end{array}
$$

The collimated fluence rate is given as (Fasano et al. 2010)

$\phi_{c}(r, z)=I \exp \left(-\mu_{t}^{\prime} z\right) \exp \left(-\frac{r^{2}}{r_{D}^{2}}\right)$

where $I\left[\mathrm{~W} / \mathrm{m}^{2}\right]$ is the surface irradiance of laser, $r_{D}$ is the radius of laser beam and $\mu_{t}^{\prime}[1 / \mathrm{m}]$ is the attenuation coefficient defined as

$\mu_{t}^{\prime}=\mu_{a}+\mu_{s}^{\prime}$.

Solution of the above-presented problems allows one to determine the Arrhenius integral (Jasiński 2013; Niemz 2007)

$A\left(r, z, t^{f}\right)=P \int_{0}^{t^{f}} \exp \left(-\frac{E}{R T(r, z, t)}\right) \mathrm{d} t$

where $P[1 / \mathrm{s}]$ is the pre-exponential factor, $E[\mathrm{~J} / \mathrm{mol}]$ is the activation energy, $R[\mathrm{~J} /(\mathrm{mol} \mathrm{K})]$ is the universal gas constant and $\left[0, t^{f}\right]$ is the time interval under consideration.

A value of damage integral $A\left(r, z, t^{f}\right)=1$ corresponds to a $63 \%$ probability of cell death at a specific point $(r, z)$, while $A\left(r, z, t^{f}\right)=4.6$ corresponds to $99 \%$ probability of cell death at this point (Chang and Nguyen 2004).

\section{Inverse Problem}

The inverse problem formulated here concerns the estimate of laser intensity $I$ which ensures the destruction of target region of biological tissue. Thus, the following criterion can be formulated:

$S(I)=\sum_{f=1}^{F} \sum_{i=1}^{M}\left[A\left(r_{i}, z_{i}, t^{f}, I\right)-A_{m}\left(r_{i}, z_{i}, t^{f}\right)\right]^{2}$

where $A_{m}\left(r_{i}, z_{i}, t^{f}\right)$ is the 'measured' Arrhenius integral. $A\left(r_{i}, z_{i}, t^{f}, I\right)$ is the calculated Arrhenius integral obtained from the direct problem solution with current estimate of the unknown parameter $I$, while $M$ is the number of points and $F$ is the number of time steps.

This inverse problem is solved using the gradient method (Kurpisz and Nowak 1995). Thus, using the necessary condition of optimum one has

$\frac{\mathrm{d} S(I)}{\mathrm{d} I}=2 \sum_{f=1}^{F} \sum_{i=1}^{M}\left[A_{i}^{f}-A_{m}\left(r_{i}, z_{i}, t^{f}\right)\right] \frac{\partial A\left(r_{i}, z_{i}, t^{f}, I\right)}{\partial I}=0$

where (c.f. Eq. 13)

$$
\begin{aligned}
V_{i}^{f} & =\frac{\partial A\left(r_{i}, z_{i}, t^{f}, I\right)}{\partial I} \\
& =P \int_{0}^{t^{f}} \frac{E}{R T^{2}\left(r_{i}, z_{i}, t\right)} \exp \left(-\frac{E}{R T\left(r_{i}, z_{i}, t\right)}\right) U\left(r_{i}, z_{i}, t\right) \mathrm{d} t
\end{aligned}
$$

while

$U\left(r_{i}, z_{i}, t\right)=\frac{\partial T\left(r_{i}, z_{i}, t\right)}{\partial I}$

are the sensitivity coefficients and $A_{i}^{f}=A\left(r_{i}, z_{i}, t^{f}, I\right)$.

Function $A_{i}^{f}$ is expanded into a Taylor series about known value of $I^{k}$, this means

$A_{i}^{f}=\left(A_{i}^{f}\right)^{k}+\left(V_{i}^{f}\right)^{k}\left(I^{k+1}-I^{k}\right)$

where $k$ is the number of iteration and $I^{k}$ for $k=0$ is the arbitrary assumed value of $I$, while $I^{k}$ for $k>0$ results from the previous iteration.

Introducing formula (18) to Eq. (15) one obtains

$\sum_{f=1}^{F} \sum_{i=1}^{M}\left[\left(A_{i}^{f}\right)^{k}+\left(V_{i}^{f}\right)^{k}\left(I^{k+1}-I^{k}\right)-A_{m}\left(x_{i}, f^{f}\right)\right]\left(V_{i}^{f}\right)^{k}=0$. 
After the mathematical manipulations one has

$$
\begin{gathered}
I^{k+1}=I^{k}+\frac{\sum_{f=1}^{F} \sum_{i=1}^{M}\left[A_{m}\left(r_{i}, z_{i}, t^{f}\right)-\left(A_{i}^{f}\right)^{k}\right]\left(V_{i}^{f}\right)^{k}}{\sum_{f=1}^{F} \sum_{i=1}^{M}\left[\left(V_{i}^{f}\right)^{k}\right]^{2}}, \\
k=0,1,2, \ldots, K
\end{gathered}
$$

where $K$ is the assumed number of iterations.

To determine the sensitivity coefficients (17), the governing equations should be differentiated with respect to the unknown parameter I (Kleiber 1997; Majchrzak and Mochnacki 2014). At first, the source function $Q_{e x}(r, z, t)$ connected with the laser irradiation is differentiated

$\frac{\partial Q_{e x}(r, z, t)}{\partial I}=\mu_{a}\left[\frac{\partial \phi_{d}(r, z)}{\partial I}+\frac{\partial \phi_{c}(r, z)}{\partial I}\right] p(t)$

or

$\frac{\partial Q_{e x}(r, z, t)}{\partial I}=\mu_{a}\left[W_{d}(r, z)+W_{c}(r, z)\right] p(t)$

where

$W_{d}(r, z)=\frac{\partial \phi_{d}(r, z)}{\partial I}, \quad W_{c}(r, z)=\frac{\partial \phi_{c}(r, z)}{\partial I}$.

Taking into account the dependence (11) one has

$W_{c}(r, z)=\exp \left(-\mu_{t}^{\prime} z\right) \exp \left(-\frac{r^{2}}{r_{D}^{2}}\right)$

while the function $W_{d}(r, z)$ results from the differentiation of Eq. (8) and boundary conditions (10). Thus $(r, z) \in \Omega: \quad D \nabla^{2} W_{d}(r, z)-\mu_{a} W_{d}(r, z)+\mu_{s}^{\prime} W_{c}(r, z)=0$

and

$(r, z) \in \Gamma: \quad-D \mathbf{n} \cdot \nabla W_{d}(r, z)=\frac{W_{d}(r, z)}{2}$

Next, Eqs. (1) and (2) are differentiated with respect to the parameter $I$ and then

$$
\begin{aligned}
C & {\left[\frac{\partial U(r, z, t)}{\partial t}+\tau_{q} \frac{\partial^{2} U(r, z, t)}{\partial t^{2}}\right] } \\
& +G\left[U_{b}(r, z, t)-U(r, z, t)\right]+\frac{\partial Q_{e x}(r, z, t)}{\partial I}
\end{aligned}
$$

$U_{b}(r, z, t)=U(r, z, t)-\frac{\varepsilon \rho_{b} c_{b}}{G} \frac{\partial U_{b}(r, z, t)}{\partial t}$

where

$U(r, z, t)=\frac{\partial T(r, z, t)}{\partial I}, \quad U_{b}(r, z, t)=\frac{\partial T_{b}(r, z, t)}{\partial I}$.

The boundary condition (3) and the initial conditions (4) (5) are also differentiated

$$
\begin{aligned}
& (r, z) \in \Gamma: \\
& -\Lambda\left[\mathbf{n} \cdot \nabla U(r, z, t)+\tau_{T} \frac{\partial[\mathbf{n} \cdot \nabla U(r, z, t)]}{\partial t}\right]=0 \\
& t=0: \quad U(r, z, t)=0,\left.\quad \frac{\partial U(r, z, t)}{\partial t}\right|_{t=0}=\frac{\partial w(r, z)}{\partial I} \\
& t=0: \quad U_{b}(r, z, t)=0 .
\end{aligned}
$$

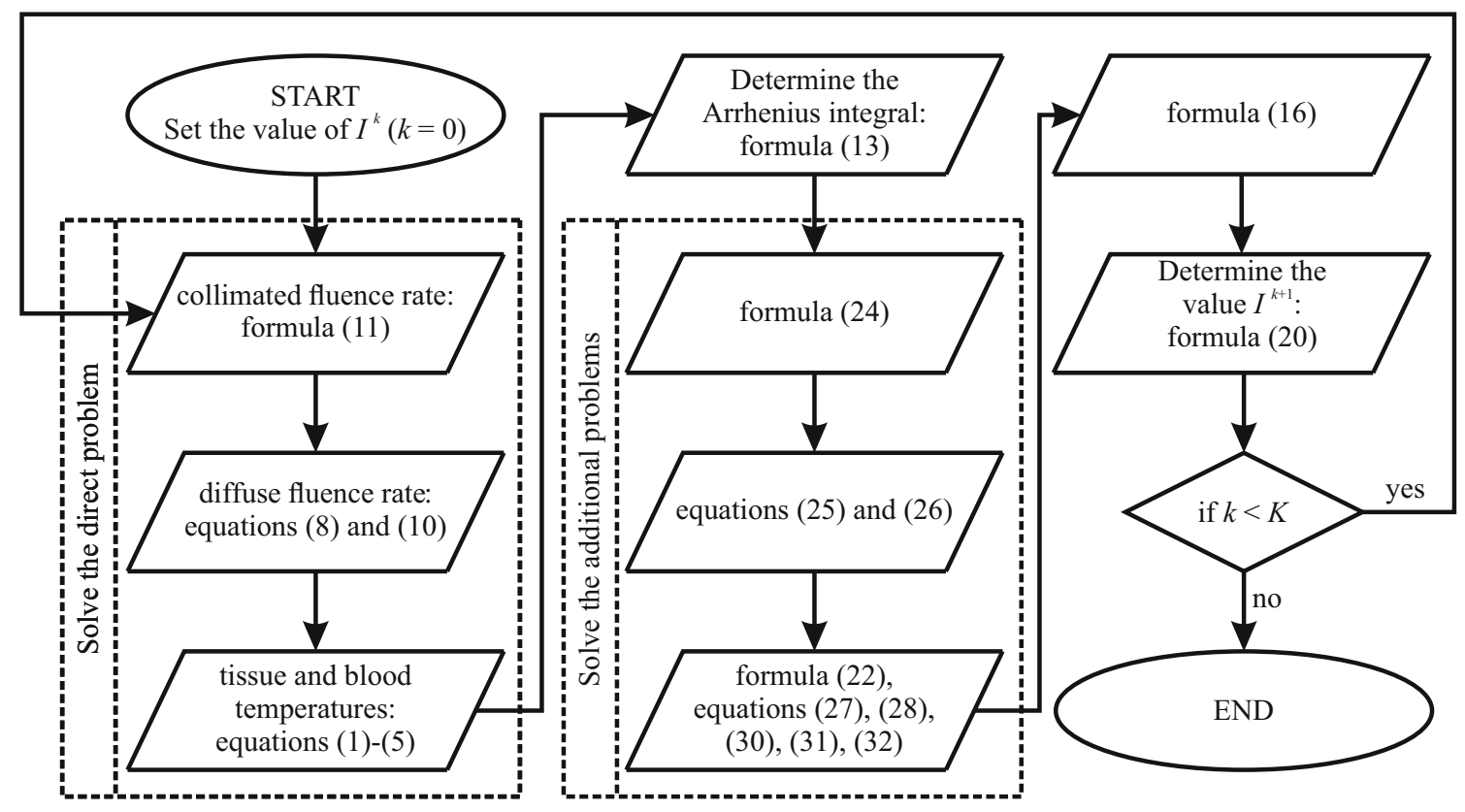

Fig. 2 Flowchart of the identification algorithm 
In Fig. 2, the summary of the identification algorithm is presented.

\section{Method of Solution}

The direct problem and additional ones connected with the sensitivity functions are solved using the finite difference method. For this purpose, the uniform spatial grid of dimensions $n \times n$ ( $h$ is the grid spacing) shown in Fig. 3 is introduced.

At first, the optical diffusion Eq. (8) is approximated

$D\left(\frac{1}{r_{i, j}} \frac{\phi_{d i, j+1}-\phi_{d i, j-1}}{2 h}+\frac{\phi_{d i, j+1}-2 \phi_{d i, j}+\phi_{d i, j-1}}{h^{2}}+\frac{\phi_{d i-1, j}-2 \phi_{d i, j}+\phi_{d i+1, j}}{h^{2}}\right)$ $-\mu_{a} \phi_{d i, j}+\mu_{s}^{\prime} \phi_{c i, j}=0$

and then $(i=1,2, \ldots, n-1, j=1,2, \ldots, n-1)$

$$
\begin{aligned}
\phi_{d i, j} & =\frac{D\left(2 r_{i, j}-h\right)}{2 r_{i, j}\left(\mu_{a} h^{2}+4 D\right)} \phi_{d i, j-1}+\frac{D\left(2 r_{i, j}+h\right)}{2 r_{i, j}\left(\mu_{a} h^{2}+4 D\right)} \phi_{d i, j+1} \\
& +\frac{D}{\mu_{a} h^{2}+4 D}\left(\phi_{d i-1, j}+\phi_{d i+1, j}\right)+\frac{\mu_{s}^{\prime} h^{2}}{\mu_{a} h^{2}+4 D} \phi_{c i, j}
\end{aligned} .
$$

The boundary conditions (10) are also approximated

$$
\begin{aligned}
& -D \frac{\phi_{d i, n}-\phi_{d i, n-1}}{h}=\frac{\phi_{d i, n}}{2} \rightarrow \phi_{d i, n}=\frac{2 D}{2 D+h} \phi_{d i, n-1}, \quad i=1,2, \ldots n-1 \\
& D \frac{\phi_{d 1, j}-\phi_{d 0, j}}{h}=\frac{\phi_{d 0, j}}{2} \quad \rightarrow \quad \phi_{d 0, j}=\frac{2 D}{2 D+h} \phi_{d 1, j}, \quad j=1,2, \ldots, n-1 \text {. } \\
& -D \frac{\phi_{d n, j}-\phi_{d n-1, j}}{h}=\frac{\phi_{d n, j}}{2} \rightarrow \phi_{d n, j}=\frac{2 D}{2 D+h} \phi_{d n-1, j}, \quad j=1,2, \ldots, n-1 \\
& D \frac{\phi_{d i, 1}-\phi_{d i, n}}{h}=0 \quad \rightarrow \quad \phi_{d i, 0}=\phi_{d i, 1}, \quad i=1,2, \ldots, n-1
\end{aligned}
$$

The system of Eqs. (34) and (35) is solved using the iterative method. In a similar way, the problem described by Eqs. (25) and (26) is solved.

Next, Eqs. (1) and (2) are approximated

$$
\begin{aligned}
& C\left[\frac{T_{i, j}^{f}-T_{i, j}^{f-1}}{\Delta t}+\frac{T_{i, j}^{f}-2 T_{i, j}^{f-1}+T_{i, j}^{f-2}}{(\Delta t)^{2}}\right] \\
& +G\left(T_{b i, j}^{f-1}-T_{i, j}^{f-1}\right)+\varepsilon Q_{m b}+(1-\varepsilon) Q_{m}+Q_{e x i, j}^{f-1}
\end{aligned}
$$

and
$T_{b i, j}^{f}=T_{i, j}^{f-1}-\frac{\varepsilon \rho_{b} c_{b}}{G} \frac{T_{b i, j}^{f}-T_{b i, j}^{f-1}}{\Delta t}$

where

$$
\begin{aligned}
\nabla^{2} T_{i, j}^{s}= & \frac{T_{i-1, j}^{s}-2 T_{i, j}^{s}+T_{i+1, j}^{s}}{h^{2}}+\frac{1}{r_{i, j}} \frac{T_{i, j+1}^{s}-T_{i, j-1}^{s}}{2 h} \\
& +\frac{T_{i, j-1}^{s}-2 T_{i, j}^{s}+T_{i, j+1}^{s}}{h^{2}}
\end{aligned}
$$

while $s=f-1$ or $s=f-2$ and $\Delta t$ is the time step.

After the mathematical manipulations one has 


$$
\begin{aligned}
T_{i, j}^{f}= & \frac{C\left(\Delta t+2 \tau_{q}\right)-G(\Delta t)^{2}}{C\left(\Delta t+\tau_{q}\right)} T_{i, j}^{f-1}-\frac{\tau_{q}}{\Delta t+\tau_{q}} T_{i, j}^{f-2} \\
& +\frac{\Lambda \Delta t\left(\Delta t+\tau_{T}\right)}{C\left(\Delta t+\tau_{q}\right)}\left[\left(\frac{1}{h^{2}}-\frac{1}{2 h r_{i, j}}\right) T_{i, j-1}^{f-1}+\left(\frac{1}{h^{2}}+\frac{1}{2 h r_{i, j}}\right) T_{i, j+1}^{f-1}+\frac{1}{h^{2}}\left(T_{i-1, j}^{f-1}+T_{i+1, j}^{f-1}\right)-\frac{4}{h^{2}} T_{i, j}^{f-1}\right] \\
& -\frac{\Lambda \Delta t \tau_{T}}{C\left(\Delta t+\tau_{q}\right)}\left[\left(\frac{1}{h^{2}}-\frac{1}{2 h r_{i, j}}\right) T_{i, j-1}^{f-2}+\left(\frac{1}{h^{2}}+\frac{1}{2 h r_{i, j}}\right) T_{i, j+1}^{f-2}+\frac{1}{h^{2}}\left(T_{i-1, j}^{f-2}+T_{i+1, j}^{f-2}\right)-\frac{4}{h^{2}} T_{i, j}^{f-2}\right] \\
& +\frac{(\Delta t)^{2}}{C\left(\Delta t+\tau_{q}\right)}\left[G T_{b i, j}^{f}+\varepsilon Q_{m b}+(1-\varepsilon) Q_{m}+Q_{e x i, j}^{f-1}\right]
\end{aligned}
$$

and

$T_{b i, j}^{f}=\frac{G \Delta t}{G \Delta t+\varepsilon \rho_{b} c_{b}}\left(T_{i, j}^{f-1}+\frac{\varepsilon \rho_{b} c_{b}}{G \Delta t} T_{b i, j}^{f-1}\right)$

The approximate form of boundary condition (3) is as follows $(i=1,2, \ldots, n-1, j=1,2, \ldots, n-1)$ :

$$
\begin{aligned}
& {[\mathbf{n} \cdot \nabla T(r, z, t)]_{i, j}^{f}} \\
& +\frac{\tau_{T}}{\Delta t}\left\{[\mathbf{n} \cdot \nabla T(r, z, t)]_{i, j}^{f}-[\mathbf{n} \cdot \nabla T(r, z, t)]_{i, j}^{f-1}\right\}=0 .
\end{aligned}
$$

It means

$$
V_{i}^{f}=P \sum_{k=1}^{f} \frac{E}{R\left(T_{i}^{k}\right)^{2}} \exp \left(-\frac{E}{R T_{i}^{k}}\right) U_{i}^{k} \Delta t
$$

\section{Results of Computations}

The cylinder of dimensions $0.02 \mathrm{~m} \times 0.02 \mathrm{~m}$ is considered. The following values of parameters are assumed: $\rho=1000 \mathrm{~kg} / \mathrm{m}^{3}, \rho_{b}=1060 \mathrm{~kg} / \mathrm{m}^{3}, c=4000 \mathrm{~J} /(\mathrm{kg} \mathrm{K}), c_{b-}$ $=3770 \mathrm{~J} /(\mathrm{kg} \mathrm{K}), \quad \lambda=\lambda_{b}=0.5 \mathrm{~W} /(\mathrm{m} \mathrm{K}), \quad \varepsilon=0.0041$, $G=34,785 \mathrm{~W} /\left(\mathrm{m}^{3} \mathrm{~K}\right), \quad \tau_{q}=0.46772 \mathrm{~s}, \quad \tau_{T}=0.46771 \mathrm{~s}$

$$
\begin{array}{lll}
\frac{\Delta t+\tau_{T}}{\Delta t} \frac{T_{i, n}^{f}-T_{i, n-1}^{f}}{h}-\frac{\tau_{T}}{\Delta t} \frac{T_{i, n}^{f-1}-T_{i, n-1}^{f-1}}{h}=0 & \rightarrow & T_{i, n}^{f}=T_{i, n-1}^{f}+\frac{\tau_{T}}{\Delta t+\tau_{T}}\left(T_{i, n}^{f-1}-T_{i, n-1}^{f-1}\right) \\
-\frac{\Delta t+\tau_{T}}{\Delta t} \frac{T_{i, 1}^{f}-T_{i, 0}^{f}}{h}+\frac{\tau_{T}}{\Delta t} \frac{T_{i, 1}^{f-1}-T_{i, 1}^{f-1}}{h}=0 & \rightarrow & T_{i, 0}^{f}=T_{i, 1}^{f}-\frac{\tau_{T}}{\Delta t+\tau_{T}}\left(T_{i, 0}^{f-1}-T_{i, 1}^{f-1}\right) \\
-\frac{\Delta t+\tau_{T}}{\Delta t} \frac{T_{1, j}^{f}-T_{0, j}^{f}}{h}+\frac{\tau_{T}}{\Delta t} \frac{T_{1, j}^{f-1}-T_{0, j}^{f-1}}{h}=0 & \rightarrow & T_{0, j}^{f}=T_{1, j}^{f}-\frac{\tau_{T}}{\Delta t+\tau_{T}}\left(T_{1, j}^{f-1}-T_{0, j}^{f-1}\right) \\
\frac{\Delta t+\tau_{T}}{\Delta t} \frac{T_{n, j}^{f}-T_{n-1, j}^{f}}{h}-\frac{\tau_{T}}{\Delta t} \frac{T_{n, j}^{f-1}-T_{n-1, j}^{f-1}}{h}=0 & \rightarrow & T_{n, j}^{f}=T_{n-1, j}^{f}+\frac{\tau_{T}}{\Delta t+\tau_{T}}\left(T_{n, j}^{f-1}-T_{n-1, j}^{f-1}\right)
\end{array}
$$

Because the explicit scheme of finite difference method is considered, the stability criterion should be determined (Majchrzak and Mochnacki 2016).

In a similar way, Eqs. (27) and (28) related to the sensitivity functions, supplemented by boundary and initial conditions (30), (31), (32) are solved.

Finally, the Arrhenius integral (13) and the sensitivity function (16) are calculated

$A_{i}^{f}=P \sum_{k=1}^{f} \exp \left(-\frac{E}{R T_{i}^{k}}\right) \Delta t$

and
(Zhang 2009), $Q_{m}=Q_{m b}=250 \mathrm{~W} / \mathrm{m}^{3}, \mu_{a}=501 / \mathrm{m}, \mu_{s-}$ $=16,9001 / \mathrm{m}, g=0.952$.

At first, the direct problem is solved under the assumption that the radius of laser beam is equal to $r_{D-}$ $=0.001 \mathrm{~m}$ and laser intensity equals $I=0.3 \mathrm{MW} / \mathrm{m}^{2}$. The initial tissue and blood temperatures are equal to $T_{p \text { - }}$ $=37{ }^{\circ} \mathrm{C}$ and initial heating rate $w(r, z)=0$. In the Arrhenius integral (13): $P=3.1 \times 10^{98} \quad 1 / \mathrm{s}$, $E=6.28 \times 10^{5} \mathrm{~J} / \mathrm{mol}, R=8.314 \mathrm{~J} /(\mathrm{mol} \mathrm{K})$. The problem is solved using explicit scheme of the finite difference method $(100 \times 100$ nodes, time step $\Delta t=0.02 \mathrm{~s})$.

In Figs. 4 and 5 the distributions of collimated fluence rate $\phi_{c}(r, z)$ and diffuse fluence rate $\phi_{d}(r, z)$ are shown, 


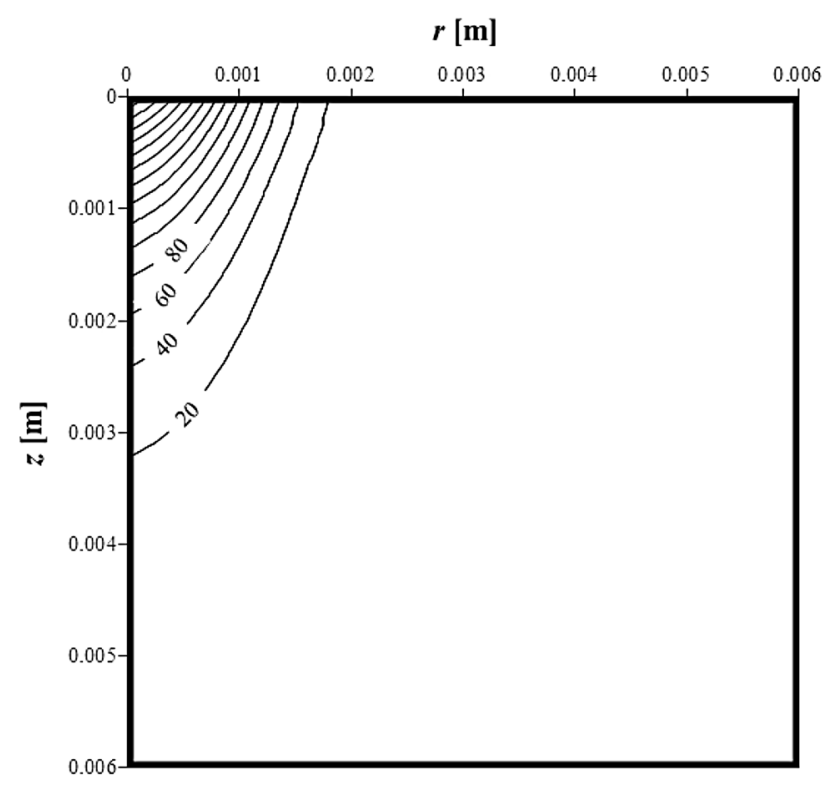

Fig. 4 Distribution of function $\phi_{c}(r, z)\left[\mathrm{kW} / \mathrm{m}^{2}\right]$

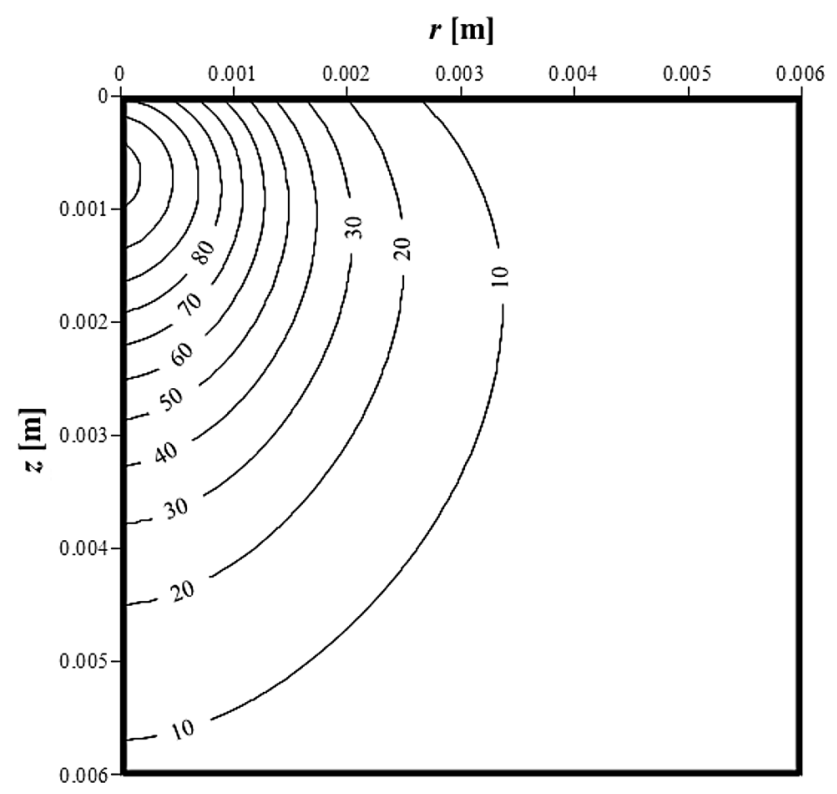

Fig. 5 Distribution of function $\phi_{d}(r, z)\left[\mathrm{kW} / \mathrm{m}^{2}\right]$

while Fig. 6 illustrates the distribution of source function $Q_{e x}(r, z)$ related to the laser irradiation. As can be seen, only in the small part of the tissue $(0 \leq r \leq 0.004 \mathrm{~m}$, $0 \leq z \leq 0.006 \mathrm{~m}$ ) the source function associated with the laser irradiation is non-zero.

Figures 7 and 8 illustrate the courses of the same functions, as previously in the $z$ direction for $r=0$. Maximal values of these functions are clearly visible.

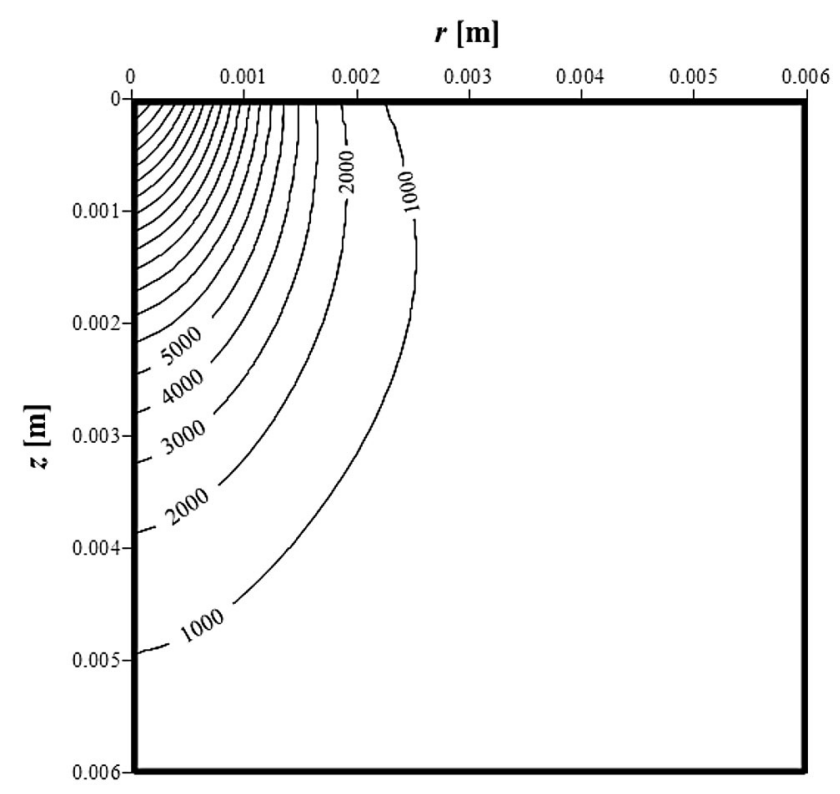

Fig. 6 Distribution of source function $Q_{e x}(r, z)\left[\mathrm{kW} / \mathrm{m}^{3}\right]$

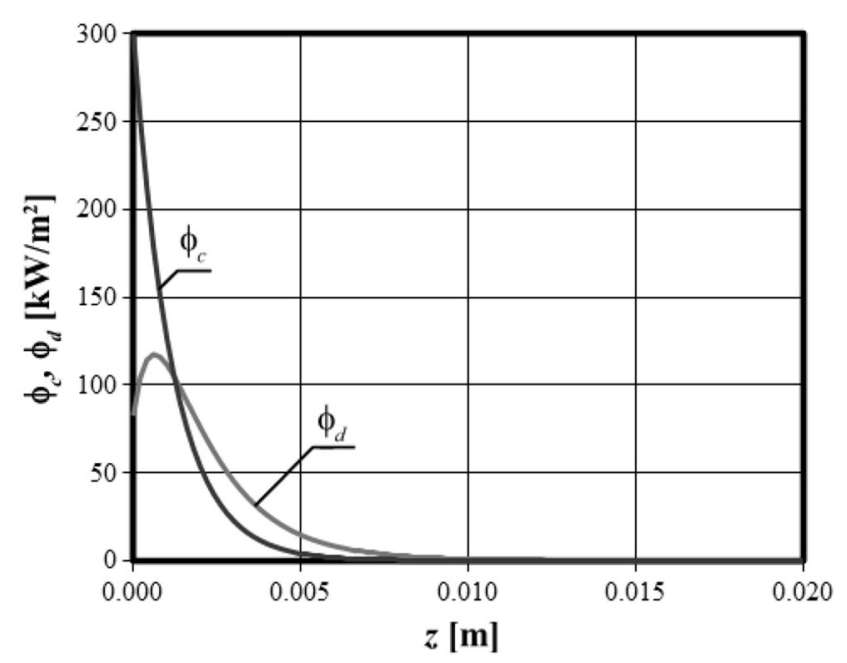

Fig. 7 Distribution of function $\phi_{c}(r, z)$ and $\phi_{d}(r, z)$ for $r=0$

The tissue temperature distributions after the time 60 and $120 \mathrm{~s}$ are shown in Figs. 9 and 10, while in Figs. 11 and 12 the distributions of Arrhenius integral for the same moments of time are presented. The subdomain marked in black (Figs. 11, 12) corresponds to this part of the tissue which is destroyed $\left(A\left(r, z, t^{f}\right) \geq 1\right)$.

It should be noted that to better illustrate the results of computations, in the Figs. 4, 5, 6, 11 and 12 only the fragment of the domain corresponding to $0 \leq r \leq 0.006$ $\mathrm{m}, 0 \leq z \leq 0.006 \mathrm{~m}$ is shown.

Next, the inverse problem is solved. Thus, on the basis of the values of Arrhenius integrals, at the nodes located in the subdomain $0 \leq r \leq 0.001 \mathrm{~m}$ and $0 \leq z \leq 0.001 \mathrm{~m}$, 


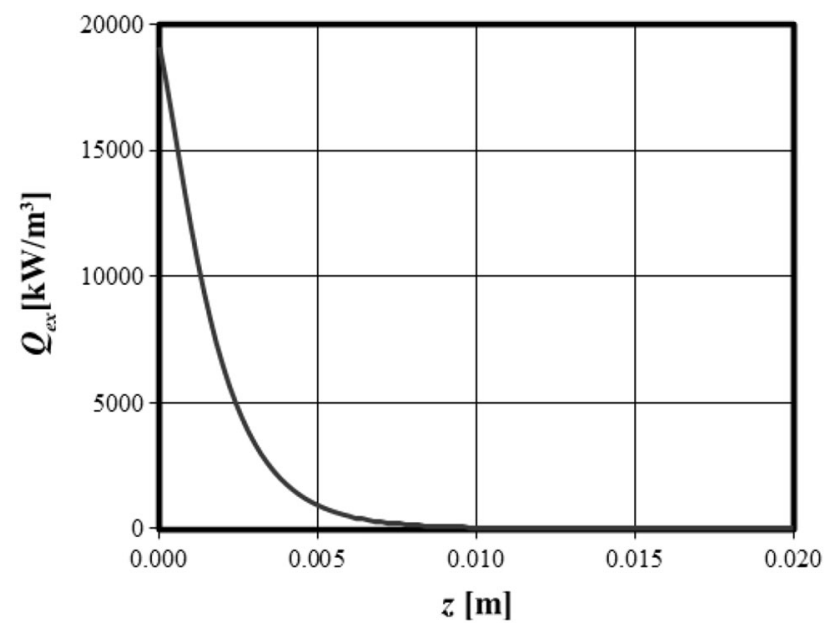

Fig. 8 Distribution of function $Q_{e x}(r, z)$ for $r=0$

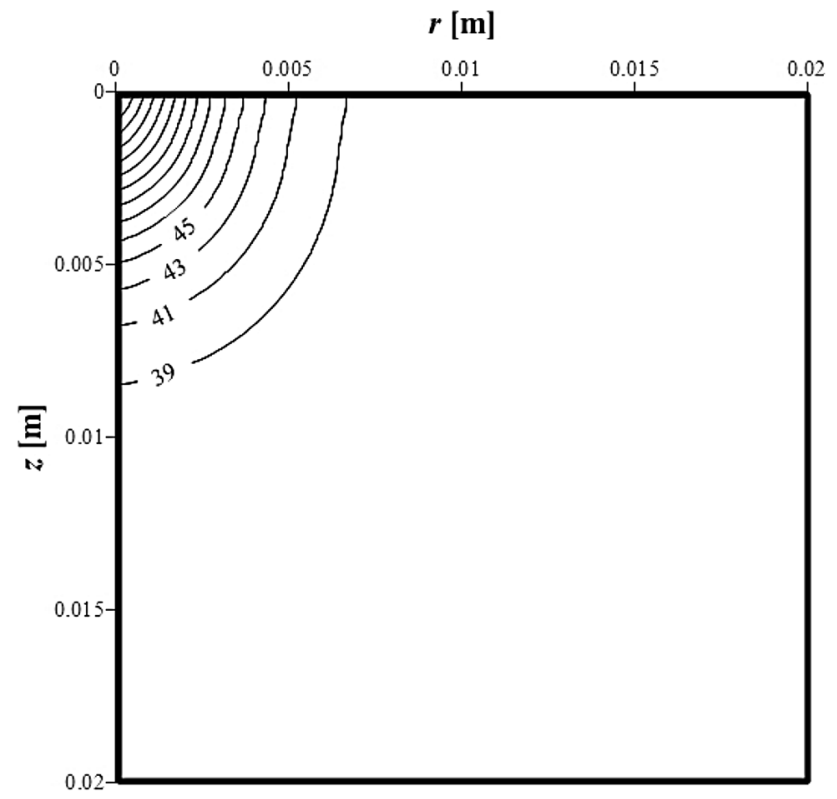

Fig. 9 Tissue temperature distribution after $60 \mathrm{~s}$

obtained from the direct problem solution the laser intensity is identified. In Fig. 13 the results for two initial values $I^{0}=0.25 \mathrm{MW} / \mathrm{m}^{2}$ and $I^{0}=0.5 \mathrm{MW} / \mathrm{m}^{2}$ are shown. For these values, the iteration process is convergent and the final value of $I$ is obtained after 20 and 25 iterations, respectively.

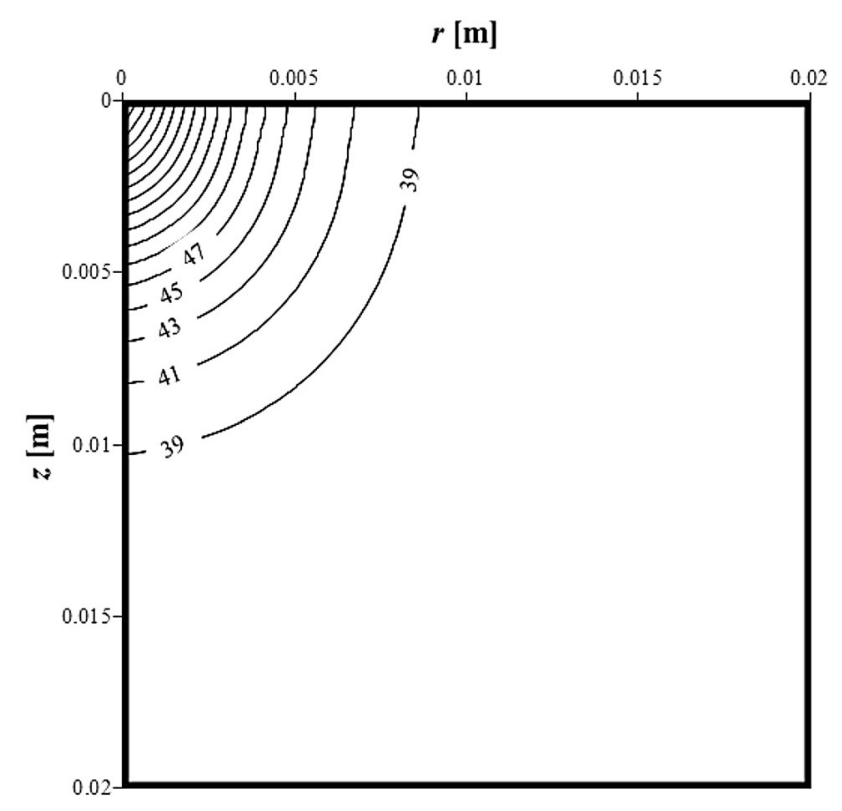

Fig. 10 Tissue temperature distribution after $120 \mathrm{~s}$

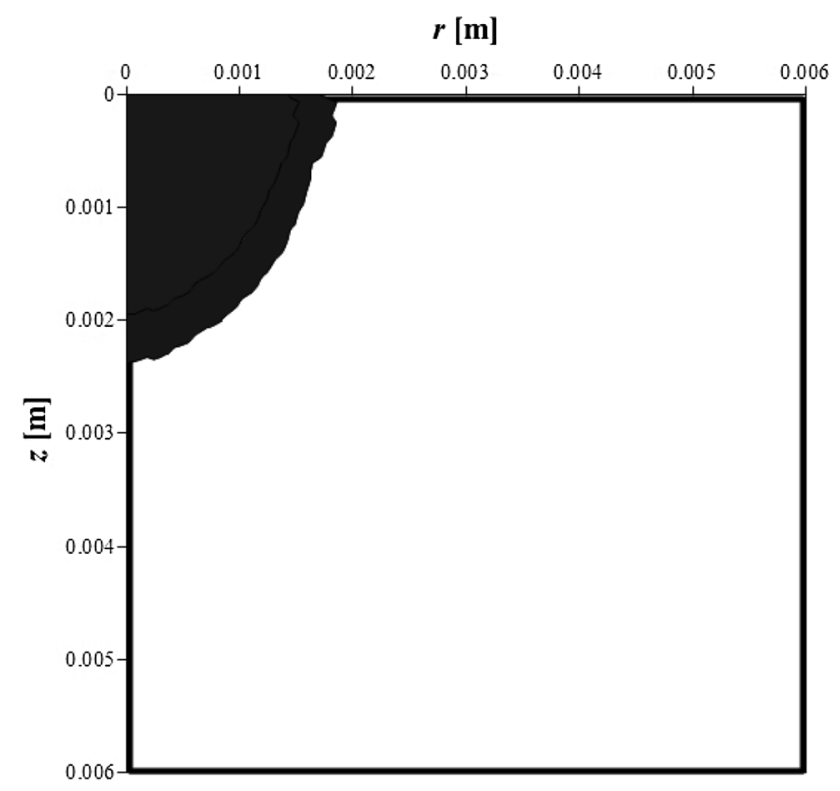

Fig. 11 Arrhenius integral distribution after $60 \mathrm{~s}$

In conclusion, it is possible to estimate the intensity of the laser which will ensure the appropriate distribution of Arrhenius integral-it means the assumed tissue destruction. 


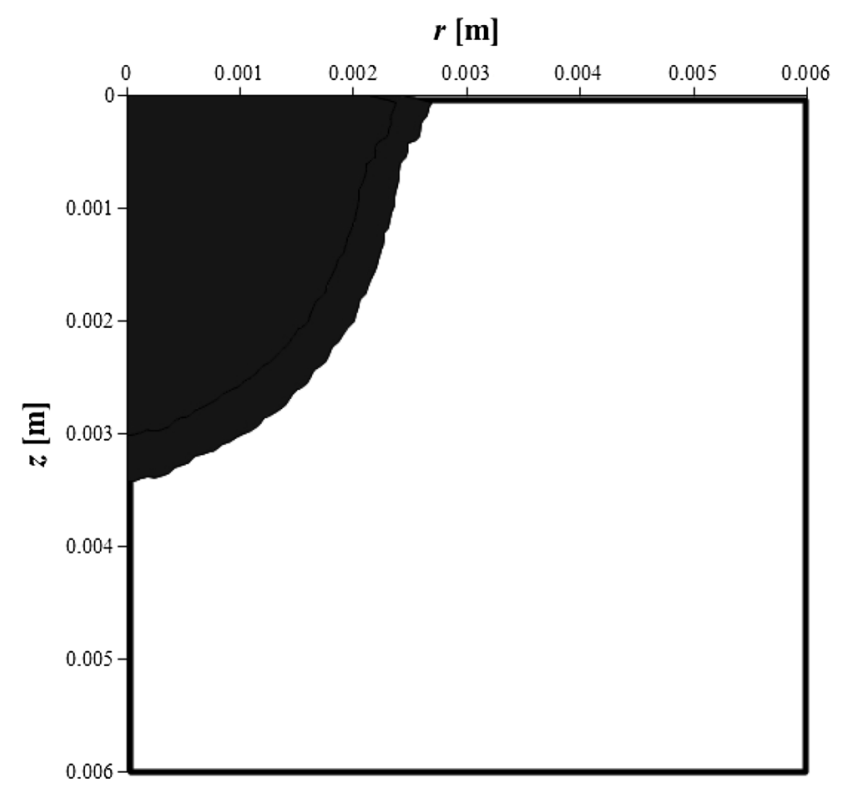

Fig. 12 Arrhenius integral distribution after $120 \mathrm{~s}$

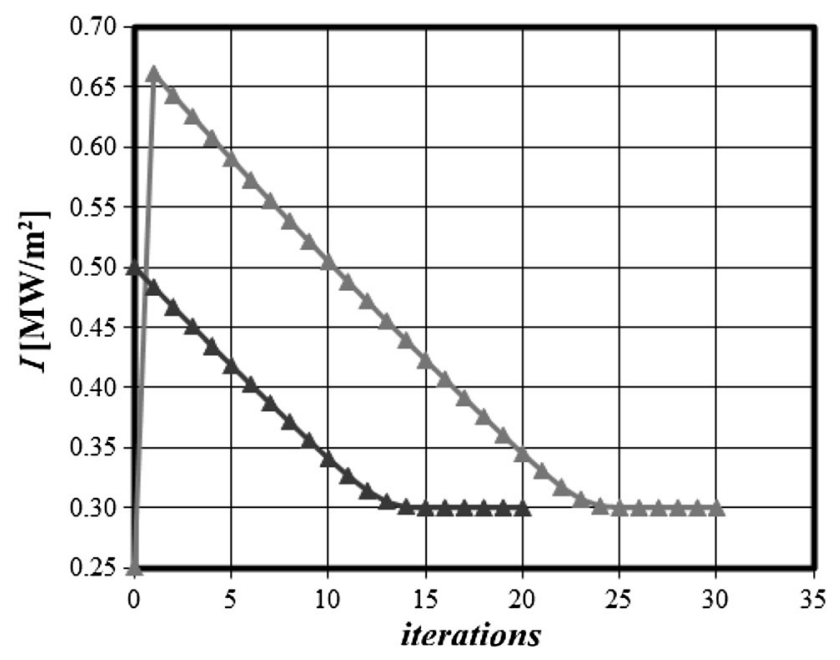

Fig. 13 Identification of laser intensity $I$ (for different initial values of I)

\section{Conclusions}

The solution of the inverse problem consisting in estimating the laser intensity which ensures the destruction of assumed tissue subdomain is presented. The temperature field in the biological tissue is described by the generalized dual-phase lag model, while the degree of tissue destruction is determined using the Arrhenius integral. The direct problem and additional one related to the sensitivity analysis are solved using the finite difference method, while to solve the inverse problem the gradient method is applied. However, it should be noted that the gradient algorithm is not always convergent. Thus, appropriate selection of the starting point $I^{0}$, which ensures convergence, is, therefore, extremely important.

Presented approach can be used, among others, in the case of electromagnetic field interaction on biological tissue, e.g. (Paruch 2017). For the postulated degree of tissue destruction it is possible to identify, for example, the voltage on the electrodes.

Acknowledgements The paper and research are financed within the Project 2015/19/B/ST8/01101 sponsored by National Science Centre (Poland).

Open Access This article is distributed under the terms of the Creative Commons Attribution 4.0 International License (http://creative commons.org/licenses/by/4.0/), which permits unrestricted use, distribution, and reproduction in any medium, provided you give appropriate credit to the original author(s) and the source, provide a link to the Creative Commons license, and indicate if changes were made.

\section{References}

Afrin N, Zhou J, Zhang Y, Tzou DY, Chen JK (2012) Numerical simulation of thermal damage to living biological tissues induced by laser irradiation based on a generalized dual phase lag model. Numer Heat Trans A Appl 61:483-501. https://doi. org/10.1080/10407782.2012.667648

Chang IA, Nguyen UD (2004) Thermal modeling of lesion growth with radiofrequency ablation devices. Biomed Eng Online 3(27):1-9. https://doi.org/10.1186/1475-925X-3-27

Dombrovsky LA (2012) The use of transport approximation and diffusion-based models in radiative transfer calculations. Comput Therm Sci 4(4):297-315. https://doi.org/10.1615/Comput ThermalScien.2012005050

Fanjul-Vélez F, Romanov OG, Arce-Diego JL (2009) Efficient 3D numerical approach for temperature prediction in laser irradiated biological tissues. Comput Biol Med 39(9):810-817. https://doi. org/10.1016/j.compbiomed.2009.06.009

Farrel TJ, Patterson MS, Wilson B (1992) A diffusion theory model of spatially resolved, steady state diffuse reflectance for the noninvasive determination of tissue optical properties in vivo. Med Phys 19(4):879-888. https://doi.org/10.1118/1.596777

Fasano A, Hömberg D, Naumov D (2010) On a mathematical model for laser-induced thermotherapy. Appl Math Model 34(12):3831-3840. https://doi.org/10.1016/j.apm.2010.03.023

Gardner CM, Jacques SL, Welch AJ (1996) Light transport in tissue: accurate expressions for one-dimensional fluence rate and escape function based upon Monte Carlo simulation. Lasers Surg Med 18:129-138. https://doi.org/10.1002/(sici)10969101(1996)18:2<129::aid-1sm2>3.0.co;2-u

Guo Z, Wan SK, Kim K, Kosaraju Ch (2003) Comparing diffusion approximation with radiation transfer analysis for light transfer in tissues. Opt Rev 10(5):415-421. https://doi.org/10.1007/ s10043-003-0415-y

He Y, Shirazaki M, Liu H, Himeno R, Sun Z (2006) A numerical coupling model to analyze the blood flow, temperature, and oxygen transport in human breast tumor under laser irradiation. Comput Biol Med 36:1336-1350. https://doi.org/10.1016/j. compbiomed.2005.08.004 
Hooshmand P, Moradi A, Kherzy B (2015) Bioheat transfer analysis of biological tissues induced by laser irradiation. Int J Therm Sci 90:214-223. https://doi.org/10.1016/j.ijthermalsci.2014.12.004

Jacques SL, Pogue BW (2008) Tutorial on diffuse light transport. J Biomed Opt 13(4):1-19. https://doi.org/10.1117/1.2967535

Jasiński M (2013) Investigation of tissue thermal damage process with application of direct sensitivity method. Moll Cell Biomech 10(3):183-199

Jasiński M, Majchrzak E, Turchan L (2016) Numerical analysis of the interactions between laser and soft tissues using generalized dual-phase lag model. Appl Math Model 40(2):750-762. https:// doi.org/10.1016/j.apm.2015.10.025

Jaunich M, Raje S, Kim K, Mitra K, Guo Z (2008) Bio-heat transfer analysis during short pulse laser irradiation of tissues. Int $\mathrm{J}$ Heat Mass Transf 51:5511-5521. https://doi.org/10.1016/j.ijheatmas stransfer.2008.04.033

Kałuża G, Majchrzak E, Turchan L (2017) Sensitivity analysis of temperature field in the heated soft tissue with respect to the perturbations of porosity. Appl Math Model 49:498-513. https:// doi.org/10.1016/j.apm.2017.05.011

Kim K, Guo Z (2007) Multi-time-scale heat transfer modeling of turbid tissues exposed to short-pulsed irradiations. Comput Meth Prog Biol 86:112-123. https://doi.org/10.1016/j.cmpb.2007.01. 009

Kim BM, Jacques SL, Rastegar S, Thomsen S, Motamedi M (1996) Nonlinear finite-element analysis of the role of dynamic changes in blood perfusion and optical properties in laser coagulation of tissue. IEEE J Sel Top Quant 2(4):922-933. https://doi.org/10. $1109 / 2944.577317$

Kleiber M (1997) Parameter sensitivity. Wiley, Chichester

Kurpisz K, Nowak AJ (1995) Inverse thermal problems. Computational Mechanics Publications, Southampton

Majchrzak E, Mochnacki B (2014) Sensitivity analysis of transient temperature field in microdomains with respect to the dual phase lag model parameters. Int J Multiscale Comput Eng 12(1):65-77. https://doi.org/10.1615/IntJMultCompEng.2014007815

Majchrzak E, Mochnacki B (2016) Dual-phase lag equation. Stability conditions of a numerical algorithm based on the explicit scheme of the finite difference method. J Appl Math Comput Mech 15(3):89-96

Majchrzak E, Turchan L, Dziatkiewicz J (2015) Modeling of skin tissue heating using the generalized dual-phase lag equation. Arch Mech 67(6):417-437

Mochnacki B, Majchrzak E (2017) Numerical model of thermal interactions between cylindrical cryoprobe and biological tissue using the dual-phase lag equation. Int $\mathrm{J}$ Heat Mass Transf
108:1-10. https://doi.org/10.1016/j.ijheatmasstransfer.2016.11. 103

Narasimhan A, Sadasivam S (2013) Non-Fourier bio heat transfer modelling of thermal damage during retinal laser irradiation. Int J Heat Mass Transf 60:591-597. https://doi.org/10.1016/j. ijheatmasstransfer.2013.01.010

Niemz MH (2007) Laser-tissue interaction: fundamentals and applications. Springer, Berlin

Paruch M (2017) Identification of the cancer ablation parameters during RF hyperthermia using gradient, evolutionary and hybrid algorithms. J Numer Methods Heat Fluid Flow 27(3):674-697. https://doi.org/10.1108/HFF-03-2016-0114

Pennes HH (1948) Analysis of tissue and arterial blood temperatures in the resting human forearm. J Appl Physiol 1:93-122

Sapareto SA, Dewey WC (1984) Thermal dose determination in cancer therapy. Int J Radiat Oncol Biol Phys 10(6):787-800

Tuchin VV (2007) Tissue optics: light scattering methods and instruments for medical diagnosis. SPIE Press, Bellingham

Vafai K (2010) Porous media: applications in biological systems and biotechnology. CRC Press, Boca Raton

Vernotte P (1958) Les paradoxes de la theorie continue de l'equation de la chaleur. CR Acad Sci I-Math 246:3154-3155

Welch AJ (1984) The thermal response of laser irradiated tissue. IEEE J Quantum Elect 20(12):1471-1481. https://doi.org/10. 1109/JQE.1984.1072339

Welch AJ, van Gemert MJC (2011) Optical-thermal response of laser irradiated tissue. Springer, Berlin

Xu F, Seffen KA, Lu TJ (2008) Non-Fourier analysis of skin biothermomechanics. Int J Heat Mass Transf 51:2237-2259. https://doi.org/10.1016/j.ijheatmasstransfer.2007.10.024

Zhang Y (2009) Generalized dual-phase lag bioheat equations based on nonequilibrium heat transfer in living biological tissues. Int $\mathrm{J}$ Heat Mass Transf 52:4829-4834. https://doi.org/10.1016/j.ijheat masstransfer.2009.06.007

Zhang Y, Chen B, Li D (2017) Non-fourier effect of laser-mediated thermal behaviors in bio-tissues: a numerical study by the dualphase-lag model. Int J Heat Mass Transf 108:1428-1438. https:// doi.org/10.1016/j.ijheatmasstransfer.2017.01.010

Zhou J, Chen JK, Zhang Y (2009a) Dual-phase lag effects on thermal damage to biological tissues caused by laser irradiation. Comput Biol Med 39:286-293. https://doi.org/10.1016/j.compbiomed. 2009.01.002

Zhou J, Zhang Y, Chen JK (2009b) An axisymmetric dual-phase-lag bioheat model for laser heating of living tissues. Int J Therm Sci 48:1477-1485. https://doi.org/10.1016/j.ijthermalsci.2008.12. 012 